\title{
Multidisciplinary treatment for patients with stage IV gastric cancer: the role of conversion surgery following chemotherapy
}

Seung-Hoon Beom ${ }^{1 \dagger}$, Yoon Young Choi ${ }^{2+}$, Song-Ee Baek ${ }^{3}$, Shuang-Xi Li ${ }^{4}$, Joon Seok Lim ${ }^{3}$, Taeil Son², Hyoung-II Kim², Jae-Ho Cheong ${ }^{2}$, Woo Jin Hyung ${ }^{2}$, Seung Ho Choi ${ }^{2}$, Minkyu Jung ${ }^{1}$, Hyo Song Kim', Hei-Cheul Jeung ${ }^{1}$, Hyun Cheol Chung ${ }^{1}$, Sun Young Rha ${ }^{1 *}$ and Sung Hoon Noh ${ }^{2^{*}}$

\begin{abstract}
Background: With advances in gastric cancer chemotherapy, conversion surgery has drawn attention as a new strategy to improve the outcome of stage IV disease. We investigated the efficacy of conversion surgery following chemotherapy for patients with stage IV gastric cancer.

Methods: We retrospectively reviewed clinico-pathologic variables and oncologic outcomes for 101 patients with stage IV gastric cancer who were treated with systemic chemotherapy followed by gastrectomy with intension of curative resection from January 2005 to December 2012.

Results: In terms of the best response from palliative chemotherapy, complete or partial response were observed in 65 patients (64.4\%) in overall. Complete response of metastatic site were observed in 72 (71.3\%) and 66 (65.3\%) patients as best and pre-operative response, respectively. The overall complete macroscopic resection, rate was 56.4\%. Eleven patients (10.9\%) received combined metastasectomy. There was no postoperative surgery-related mortality for 1 month. The median overall survival time was 26.0 months. Multivariable analysis identified complete macroscopic resection, chemotherapy response (complete response/partial response) of metastatic sites, and change in CEA level as independent prognostic factors contributing to overall survival.

Conclusions: Patients with stage IV gastric cancer who exhibit a good clinical response to chemotherapy might obtain greater survival benefit from gastrectomy following chemotherapy compared with patients who exhibit a poor response to chemotherapy. Prospective, randomized trials are required to determine the best strategy for combining initial chemotherapy with subsequent gastrectomy.
\end{abstract}

Keywords: Gastric cancer, Metastasis, Gastrectomy, Chemotherapy, Conversion surgery

\footnotetext{
* Correspondence: RHA7655@yuhs.ac; SUNGHOONN@yuhs.ac

† Seung-Hoon Beom and Yoon Young Choi contributed equally to this work.

${ }^{1}$ Department of Internal Medicine, Yonsei Cancer Center, Yonsei University

College of Medicine, 50-1 Yonsei-ro, Seodaemun-gu, Seoul 120-752,

Republic of Korea

${ }^{2}$ Department of Surgery, Yonsei Cancer Center, Yonsei University College of

Medicine, 50-1 Yonsei-ro, Seodaemun-gu, Seoul 120-752, Republic of Korea

Full list of author information is available at the end of the article
}

(c) The Author(s). 2018 Open Access This article is distributed under the terms of the Creative Commons Attribution 4.0 International License (http://creativecommons.org/licenses/by/4.0/), which permits unrestricted use, distribution, and reproduction in any medium, provided you give appropriate credit to the original author(s) and the source, provide a link to the Creative Commons license, and indicate if changes were made. The Creative Commons Public Domain Dedication waiver (http://creativecommons.org/publicdomain/zero/1.0/) applies to the data made available in this article, unless otherwise stated. 


\section{Background}

Despite a declining incidence in many developed countries, gastric cancer remains the second most common cause of cancer-related deaths in the world [1,2]. Although the prognosis of metastatic gastric cancer is poor, combination chemotherapy improved the quality of life and overall survival (OS) compared with the best supportive care in several randomized studies [3, 4]. In general, 5-fluorouracil (5-FU)-based or cisplatin-based combination regimens are widely accepted as potential standard therapies with a response rate of around $30-40 \%$ and median OS of 911 months [5, 6]. More recently, even greater progress has been achieved by combining conventional chemotherapy with a targeted monoclonal antibody (median OS, 13.8 months) [7]. Although a large proportion of patients with metastatic or recurrent gastric cancer respond initially to chemotherapy, the disease ultimately progresses. In addition, a substantial proportion of patients have primary refractory diseases. Therefore, novel therapeutic strategies for treating metastatic gastric cancer are required.

Currently, surgery is not a standard treatment option for patients with gastric cancer with distant metastasis, except for those who need palliative surgery for bleeding, obstruction, or perforation caused by the tumor. Recently, a randomized, controlled trial of reduction surgery plus chemotherapy versus chemotherapy alone for M1 gastric cancer (REGATTA trial) failed to show any efficacy of surgery [8]. Recent advances in chemotherapy for gastric cancer have raised new clinical questions regarding the role of surgical intervention for patients with a good chemotherapy response, even if the patients have distant metastasis. Surgery for those patients might provide long-term survival benefit by removing macroscopic lesions remaining after chemotherapy. That type of surgery, referred to as conversion surgery, aims to cure the disease, rather than just provide palliative treatment, on the basis of the response to chemotherapy, as is done for initially unresectable colorectal cancer [9]. However, the clinical value of such multimodal therapy combining chemotherapy and conversion surgery for stage IV gastric cancer remains controversial.

The aim of this study was to evaluate the efficacy and feasibility of surgery in patients with stage IV gastric cancer who were treated by gastrectomy following chemotherapy, with a particular focus on the selection of patients who might benefit from conversion surgery.

\section{Methods}

\section{Patients}

We retrospectively identified patients with a clinical diagnosis of stage IV gastric cancer who underwent gastrectomy following chemotherapy in Yonsei Cancer Center from January 2005 through December 2012. The key eligibility criteria were: (i) patients with histologically proven gastric cancer, (ii) who received systemic chemotherapy at the time of diagnosis of stage IV disease according to the AJCC 7th staging system, and (iii) underwent subsequent gastrectomy with the intention of curative resection. Consecutive patients corresponding to those criteria were included. We initially identified 106 patients who underwent gastrectomy following chemotherapy. Four patients were excluded because the aim of surgery was palliative (two patients underwent gastrectomy because of bleeding, and two patients did so because of gastric obstruction). One additional patient who received initial chemotherapy at another institution was excluded from the analysis, because there were no available clinical data from the time of diagnosis. Thus, we analyzed 101 patients (Additional file 1: Figure S1). This study was approved by the Institutional Review Board of Severance Hospital, Yonsei University College of Medicine (4-2016-0408).

\section{Variables for analyses}

We grouped the variables collected for study into four categories: baseline characteristics, chemotherapy-related information, variables before operation, and surgical outcomes including pathologic results. The baseline characteristics included age, gender, clinical $\mathrm{T}$ and $\mathrm{N}$ stage, type of distant metastasis, neutrophil / lymphocyte ratio (NLR, \%), systemic immune-inflammation index (SII, platelet count $x$ neutrophil count / lymphocyte count), and albumin level $(\mathrm{g} / \mathrm{dL})$ at initial diagnosis. The chemotherapy-related information included the regimen of palliative chemotherapy; the best response and preoperative response (response at the time before operation) to palliative chemotherapy overall, at the local region, and at the metastatic sites; number of cycles of chemotherapy. The response to chemotherapy was defined according to RECIST criteria version 1.1 and categorized as complete response (CR), partial response (PR), stable disease (SD), or progressive disease (PD) [10]. The variables before operation included the change in body mass index (BMI), the change in tumor markers, the clinical $\mathrm{T}$ and $\mathrm{N}$ stage immediately prior to surgery, and during the time interval between the initial diagnosis and surgery. Clinical $\mathrm{T}$ and $\mathrm{N}$ stage was evaluated by one radiologist with CT images according to AJCC 7th guideline. We assumed stomach lesion with definite extramural fat infiltration or adjacent organ invasion as clinical T4 lesion. The patients were classified into three categories based on BMI $\left(\mathrm{kg} / \mathrm{m}^{2}\right)$ in the period between diagnosis and surgery: underweight $(\mathrm{BMI}<17.5)$, overweight $(\mathrm{BMI} \geq 23.0)$, and normal $(17.5 \leq \mathrm{BMI}<23.0)$. The changes in the carcinoembryonic antigen (CEA) and carbohydrate antigen (CA 199) tumor markers between the initial diagnosis and surgery were classified as stable (no change), improved (high levels decreased to the normal range), worse (normal levels increased to the high range), and not available (with any missing value). The surgical outcomes included the presence of peritoneal infiltration, whether or not 
metastasectomy was performed, the extent of gastrectomy and lymph node (LN) dissection, and curative resection. In this study, curative resection means complete macroscopic resection (CMR) which was defined there was no visible tumor in abdomen after surgery. We also considered variables of the pathologic $\mathrm{T}$ and $\mathrm{N}$ stage, the Lauren classification of the surgical specimen, and presence of postoperative chemotherapy as potential prognostic factors.

\section{Statistical analysis}

We analyzed categorical variables based on the proportions among the patients and continuous variables based on the mean and standard deviation. The primary outcome was OS, defined as the time from the diagnosis of gastric cancer to the time of death by any cause. We generated survival curves by the Kaplan-Meier method and compared them by log-rank tests. We used a Cox proportional hazard regression model to identify risk factors for OS. We described the risk factors by a hazard ratio (HR) with 95\% confidence interval (CI). We conducted a multivariable Cox analysis with the variables that had $p$-value $\leq 0.10$ in the univariable analyses. We selected the final model by the forward likelihood ratio method. Two-tailed $p$-value $\leq 0.05$ was considered statistically significant. All analyses were conducted using SPSS (version 19.0 software, IBM SPSS, Chicago, IL).

\section{Results}

\section{Characteristics of the patients}

The median age of the enrolled patients was 52 years (Table 1). The study population was $59.4 \%$ male. At the time of diagnosis, $80.2 \%$ of the patients were suspected to have clinically serosa-positive depth of invasion, and $84.2 \%$ of the patients were suspected to be beyond the clinical N1 stage. The reasons for diagnosis of stage IV disease varied, including peritoneal carcinomatosis (32.7\%), liver metastasis (10.9\%), distant LN metastasis (34.7\%), Krukenberg tumor (20.0\%), and two or more distant metastases (19.8\%). The mean baseline values of NLR, SII, and albumin were $2.67,9.14$, and 3.94, respectively.

The preoperative chemotherapy regimen was platinum plus fluoropyrimidine in $50.5 \%$ of the patients, taxane plus fluoropyrimidine in $11.9 \%$ of the patients, platinum plus taxane plus fluoropyrimidine in $14.9 \%$ of the patients, taxane plus platinum in $15.8 \%$ of the patients, and others in $6.9 \%$ of the patients. Overall, 64.4 and $59.4 \%$ of the patients had CR or PR to preoperative chemotherapy as best response and preoperative response to the chemotherapy, respectively. When the responses were divided into the local region and the metastatic sites, the rate of CR/PR was lower in the local region $(46.5$ and $42.6 \%)$ than in the metastatic sites $(83.2$ and $77.2 \%$ ) in both best response and preoperative response. CR of metastatic site was observed in 72 (71.3\%) and $66(65.3 \%)$ patients in best and preoperative response, respectively. The median number of cycles of chemotherapy was 6 (1-32 cycles).

Nine patients $(8.9 \%)$ were considered underweight during chemotherapy treatment, and $52.5 \%$ of the patients were considered overweight. The levels of CEA and CA19-9 improved in 16 and 10 patients, respectively, and worsened in 3 and 5 patients, respectively. After the initial chemotherapy, both the $\mathrm{T}$ and the $\mathrm{N}$ staging was downgraded in overall; the proportion of serosa-negative was $47.5 \%$ and that of N0/N1 was $32.7 \%$. The interval from chemotherapy to surgery was $\leq 24$ weeks in 51 patients.

During the surgery, 32 patients displayed peritoneal infiltration. Metastasectomy was conducted for 11 patients (three hepatectomy, six para-aortic LN dissection, and three oophorectomy). Fifty-seven patients underwent total gastrectomy, and 76 patients underwent $\geq$ D2 LN dissection. Finally, CMR was achieved in 57 patients $(56.4 \%)$, and 46 and 42 patients were found to have intestinal and diffuse-type gastric cancer, respectively. In the final pathologic diagnosis, 54 (53.5\%) of the patients were serosa positive (pT4a/b), and 66 of the patients (65.3\%) had $\geq 3$ metastatic LNs. Eighty-four patients were treated with postoperative chemotherapy. There was no postoperative surgery-related mortality for 1 month. The detailed information is summarized in Table 1.

\section{Prognostic factors in the population}

The median follow-up duration was 63.3 months. Seventy-three patients (72.3\%) died during follow up. The median OS of the patients was 26.0 (95\% CI, 21.6-30.3) months. Figure 1a depicts the different prognoses by the type of distant metastasis. Compared with the prognoses for patients with other types of distant metastasis, the prognosis for patients with liver metastasis (median survival, 49.2 months) was better, and that for patients with Krukenberg tumor (median survival, 13.6 months) was worse. In the univariate Cox analyses, greater age was related to better OS $(p=0.047)$, whereas other baseline characteristics such as gender, initial clinical $\mathrm{T}$ and $\mathrm{N}$ stage, and initial NLR, SII, and albumin levels were not statistically significant (Table 2).

There was no difference in prognosis based on the regimen of preoperative chemotherapy (Fig. 1b and Table 2). The overall response to chemotherapy was not statistically significant to the prognosis in both best and preoperative response (log-rank $p=0.199,0.634$, respectively, Fig. 2a and $\mathrm{d}$ ). The response of local region to chemotherapy showed similar prognosis in both best and preoperative response (log-rank $p=0.575,0.875$, respectively, Fig. $2 \mathrm{~b}$ and e). However, CR/PR at the metastatic sites was significantly related to $\mathrm{OS}$ in both best and preoperative response ( $\log$-rank $p=0.011$ and 0.018, respectively, Fig. 2c and $\mathrm{f}$ ) and univariate HRs were also statistically significant (HR 
Table 1 Characteristics of the enrolled patients $(n=101)$

\begin{tabular}{|c|c|c|c|c|c|c|c|}
\hline \multicolumn{2}{|c|}{ Baseline Characteristics } & \multicolumn{2}{|l|}{ Chemotherapy } & \multicolumn{2}{|l|}{ Preoperative } & \multirow{2}{*}{\multicolumn{2}{|c|}{$\frac{\text { Surgical Outcomes }}{\text { Peritoneal infiltration }}$}} \\
\hline $\begin{array}{l}\text { Age, median, } \\
\text { years }\end{array}$ & 52 (range 26-78) & Regimen & & BMl & & & \\
\hline \multicolumn{2}{|l|}{ Gender } & Platinum + FU & $51(50.5)$ & Normal & 39 (38.6) & No & $69(68.3)$ \\
\hline Male & $60(59.4)$ & Taxane + FU & $12(11.9)$ & Under weight & $9(8.9)$ & Yes & $32(31.7)$ \\
\hline Female & $41(40.6)$ & Platinum + Taxane + FU & $15(14.9)$ & Over weight & $53(52.5)$ & Metastasectomy & \\
\hline \multicolumn{2}{|l|}{ cT stage } & Taxane + Platinum & $16(15.8)$ & \multicolumn{2}{|l|}{ Change of CEA level } & No & $90(89.1)$ \\
\hline $\begin{array}{l}\text { Serosa } \\
\text { negative }\end{array}$ & $20(19.8)$ & Others & $7(6.9)$ & Stable & $66(65.3)$ & Yes & $11(10.9)$ \\
\hline Serosa positive & $81(80.2)$ & Best response & & Improved & $16(15.8)$ & Hepatectomy & 3 \\
\hline \multicolumn{2}{|l|}{ cN stage } & Overall & & Worse & $3(3.0)$ & \#16 & 6 \\
\hline No/N1 & $16(15.8)$ & CR/PR & $65(64.4)$ & NA & $16(15.8)$ & Oophorectomy & 3 \\
\hline N2/N3 & $85(84.2)$ & SD/PD & 36 (35.6) & \multicolumn{2}{|c|}{ Change of CA19-9 level } & \multicolumn{2}{|l|}{ Extent of gastrectomy } \\
\hline \multicolumn{2}{|c|}{ Type of distant metastasis } & Local region & & Stable & $66(65.3)$ & TG & $57(56.4)$ \\
\hline $\begin{array}{l}\text { Peritoneal } \\
\text { carcinomatosis }\end{array}$ & $33(32.7)$ & $C R / P R$ & $47(46.5)$ & Improved & $10(9.9)$ & DG & $44(43.6)$ \\
\hline $\begin{array}{l}\text { Liver } \\
\text { metastasis }\end{array}$ & $11(10.9)$ & SD/PD & $54(53.5)$ & Worse & $5(5.0)$ & Extent of LND & \\
\hline $\begin{array}{l}\text { Distant LN } \\
\text { metastasis }\end{array}$ & $35(34.7)$ & Metastatic site & & NA & $20(19.8)$ & $<\mathrm{D} 2$ & $25(24.8)$ \\
\hline $\begin{array}{l}\text { Krukenberg } \\
\text { tumor }\end{array}$ & $2(2.0)$ & $\mathrm{CR} / \mathrm{PR}$ & $84(83.2)$ & Pre_op cT stage & & $\geq \mathrm{D} 2$ & $76(75.2)$ \\
\hline $\begin{array}{l}\text { Any } \\
\text { combination }\end{array}$ & $20(19.8)$ & SD/PD & $17(16.8)$ & Serosa negative & $48(47.5)$ & Complete macroscopic resec & ction \\
\hline $\begin{array}{l}\text { NLR (Neut/ } \\
\text { lympho) }\end{array}$ & $2.67 \pm 1.30$ & Preoperative response & & Serosa positive & $53(52.5)$ & Yes & $57(56.4)$ \\
\hline $\begin{array}{l}\text { SII (PLT*Neut/ } \\
\text { lympho) }\end{array}$ & $9.14 \pm 6.88$ & Overall & & Pre_op cN stage & & No & $44(43.6)$ \\
\hline \multirow[t]{13}{*}{ Albumin (g/dL) } & $3.94 \pm 0.53$ & $\mathrm{CR} / \mathrm{PR}$ & $60(59.4)$ & N0/N1 & $33(32.7)$ & pT stage & \\
\hline & & SD/PD & $41(40.6)$ & N2/N3 & $68(67.3)$ & Serosa negative (pT1-3) ${ }^{4}$ & $47(46.5)$ \\
\hline & & Local region & & Interval to surgery & & \multicolumn{2}{|c|}{ Serosa positive (pT4a/b) } \\
\hline & & $C R / P R$ & $43(42.6)$ & $\leq 24$ weeks & $51(50.5)$ & \multicolumn{2}{|l|}{ pN stage } \\
\hline & & $\mathrm{SD} / \mathrm{PD}$ & $58(57.4)$ & $>24$ weeks & $50(49.5)$ & $\mathrm{pNO} / \mathrm{N} 1$ & $35(34.7)$ \\
\hline & & Metastatic site & & & & $\mathrm{pN2/N3}$ & $66(65.3)$ \\
\hline & & $C R / P R$ & $78(77.2)$ & & & \multicolumn{2}{|l|}{ Lauren classification } \\
\hline & & $\mathrm{SD} / \mathrm{PD}$ & $23(22.8)$ & & & Intestinal & $46(45.5)$ \\
\hline & & $\begin{array}{l}\text { Number of Cycles } \\
\text { of Chemotherapy }\end{array}$ & 6 (range 1-32) & & & Diffuse & $42(41.6)$ \\
\hline & & $\leq 6$ cycles & $62(61.4)$ & & & Others & $13(12.9)$ \\
\hline & & $>6$ cycles & 39 (38.6) & & & \multicolumn{2}{|l|}{ Postoperative chemotherapy } \\
\hline & & & & & & No & $17(16.8)$ \\
\hline & & & & & & Yes & $84(83.2)$ \\
\hline
\end{tabular}

LN lymph node, NLR neutrophil lymphocyte ratio, SIl systematic immune-inflammation index, $C R$ complete response, $P R$ partial response, $S D$ stable disease, $P D$ progressive disease, BMI body mass index, CEA carcinoembryonic antigen, CA19-9 carbohydrate antigen 19-9, TG total gastrectomy, DG distal gastrectomy, LND lymph node dissection, FU fluoropyrimidine

for best response: 2.105 [1.171-3.783], $p=0.013$, HR for preoperative response: 1.850 [1.103-3.103], $p=0.020$, Table 2).
Among the preoperative variables, BMI and changed CEA level was related to prognosis (Fig. $3 a$ and b, and Table 2): patients experienced underweight were related 

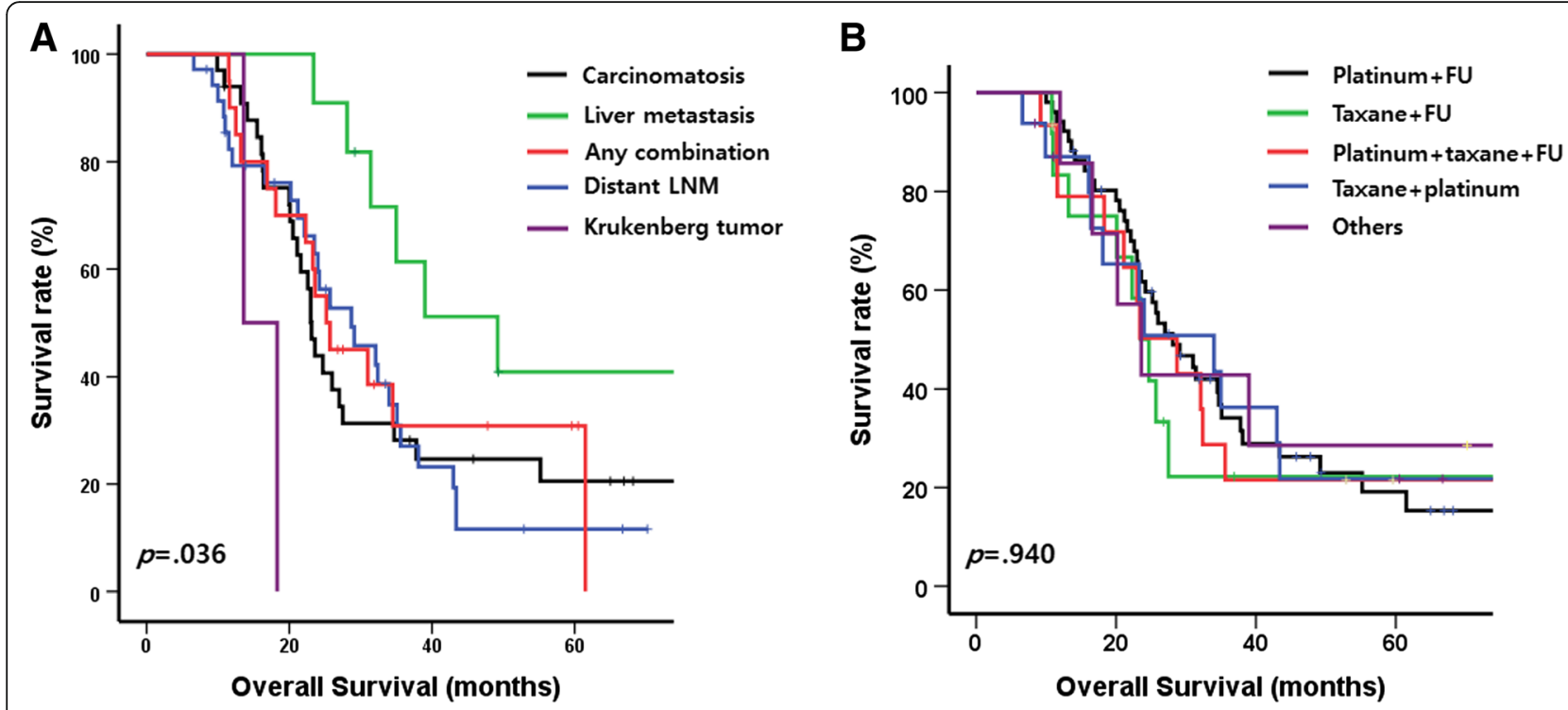

Fig. 1 Kaplan-Meier curves with log-rank test for overall survival of the patients with stage IV gastric cancer who treated by gastrectomy following chemotherapy a) according to the type of distant metastasis, b) and chemotherapy regimen

to poor prognosis $(p=0.002)$ and patients with improved CEA level were related good prognosis $(p=0.003)$. Other variables such as changed CA19-9 level, preoperative clinical $\mathrm{T}$ and $\mathrm{N}$ stage, and interval to surgery were not related to the prognosis (Fig. 3c-f and Table 2).

Figure 4 and Table 2 showed the prognosis of each variable of surgical outcomes. The presence of peritoneal infiltration ( $p=0.001$, Fig. 4a), extent of gastrectomy ( $p=0.007$, Fig. $4 \mathrm{~b})$, CMR $(p<0.001$, Fig. $4 \mathrm{~d})$, pathologic T stage $(p=0.002$, Fig. $4 \mathrm{f})$, Lauren classification $(p=0.001$, Fig. 4e) were related to the prognosis, and univariable Cox analysis showed similar results (Table 2). Other factors such as metastasectomy, extent of LN dissection, pathologic $\mathrm{N}$ stage, and postoperative chemotherapy were not related to OS (Fig. 4c, g, h and Table 2).

The multivariable analysis was conducted with the variables that had $p$-value $<0.1$ in the univariate analyses (age, type of distant metastasis, best response of the metastatic sites, BMI, change in CEA level, preoperative cT stage, presence of peritoneal infiltration, extent of gastrectomy, CMR, pT stage, and Lauren classification). The best response of the metastatic sites [HR: 1.822 (0.999-3.323), $p=0.050$ ], change in CEA level [HR of improved, worse, and NA compared with stable: $0.564(0.259-1.226), p=$ $0.148 ; 5.013$ (1.477-17.017), $p=0.010 ; 0.973$ (0.5041.877), $p=0.935$; respectively; overall $p=0.024$ ], and CMR [HR: 1.998 (1.233-3.238), $p=0.005$ ] were selected as factors that related to the prognosis of the patients (Table 3 ).

\section{Subgroup analyses by the type of distant metastasis}

Subgroup analyses according to the type of distant metastasis were conducted to evaluate the effects of the variables that were selected for the final model (best response of metastatic sites, change in CEA level, and CMR). In the patients with peritoneal carcinomatosis, there was no trend for the best response of metastatic sites or change in CEA level (Additional file 2: Figure S2A and B), and CMR was marginally related to better survival but was not statistically significant $(\log -\operatorname{rank} p=$ 0.064, Additional file 2: Figure S2C). There were no remarkable trends among the patients with liver metastasis (Additional file 3: Figure S3A-C) and distant LN metastasis (Additional file 4: Figure S4A-C), respectively. Among the patients with two or more distant metastases, the best response of the metastatic sites was related to OS ( $\log$-rank $p=0.007$, Additional file 5: Figure S5A), and there were trends for better prognosis with improved CEA level and CMR, respectively, although those trends were not statistically significant (Additional file 5: Figure S5B and C).

\section{Discussion}

Patients with stage IV gastric cancer usually have a poor prognosis and are primarily considered for systemic chemotherapy, but not for surgery. The exception to that is patients who require rapid palliation of cancer-related complications such as bleeding or obstruction [11]. Recent advances in gastric-cancer chemotherapy, including the introduction of new anticancer agents and the development of multi-agent regimens, have made complete macroscopic resection possible in some patients with stage IV gastric cancer. That strategy of treatment is referred to as conversion gastrectomy with curative intent and is distinct from palliative gastrectomy. The results 
Table 2 Univariate Cox proportional hazard model of overall survival by each variable

\begin{tabular}{|c|c|c|c|c|c|}
\hline Baseline Characteristics & HR $(95 \% \mathrm{Cl})$ & $p$-value & Chemotherapy & $\mathrm{HR}(95 \% \mathrm{Cl})$ & $p$-value \\
\hline Age & $0.978(0.958-1.000)$ & 0.047 & Regimen & & 0.941 \\
\hline Gender & & 0.111 & Platinum + FU & 1 & \\
\hline Male & 1 & & Taxane + FU & $1.336(0.643-2.776)$ & 0.437 \\
\hline Female & $1.464(0.916-2.339)$ & & Platinum + Taxane + FU & $1.116(0.569-2.188)$ & 0.750 \\
\hline cT stage & & 0.734 & Taxane + Platinum & $1.003(0.511-1.969)$ & 0.994 \\
\hline Serosa negative & 1 & & Others & $0.904(0.354-2.306)$ & 0.832 \\
\hline Serosa positive & 1.107 (0.616-1.988) & & Best response & & \\
\hline cN stage & & 0.743 & Overall & & 0.201 \\
\hline No/N1 & 1 & & $C R / P R$ & 1 & \\
\hline N2/N3 & $1.109(0.597-2.061)$ & & $\mathrm{SD} / \mathrm{PD}$ & 1.359 (0.849-2.175) & \\
\hline Type of distant metastasis & & 0.065 & Local region & & 0.576 \\
\hline Peritoneal carcinomatosis & 1 & & CR/PR & 1 & \\
\hline Liver metastasis & $0.407(0.166-0.994)$ & 0.049 & $\mathrm{SD} / \mathrm{PD}$ & $1.142(0.717-1.817)$ & \\
\hline Distant LN metastasis & $1.025(0.590-1.780)$ & 0.930 & Metastatic site & & 0.013 \\
\hline Krukenberg tumor & $4.423(1.004-19.487)$ & 0.049 & $C R / P R$ & 1 & \\
\hline Any combination & $0.900(0.467-1.735)$ & 0.753 & $\mathrm{SD} / \mathrm{PD}$ & $2.105(1.171-3.783)$ & \\
\hline NLR (Neut/lympho) & 1.349 (0.837-2.177) & 0.219 & Preop. response & & \\
\hline SII (PLT*Neut/lympho) & $1.252(0.776-2.019)$ & 0.357 & Overall & & 0.635 \\
\hline Albumin & & 0.986 & CR/PR & 1 & \\
\hline low & 1 & & $\mathrm{SD} / \mathrm{PD}$ & $1.119(0.704-1.777)$ & \\
\hline \multirow[t]{9}{*}{ normal } & $1.006(0.480-2.108)$ & & Local region & & 0.875 \\
\hline & & & $\mathrm{CR} / \mathrm{PR}$ & 1 & \\
\hline & & & $\mathrm{SD} / \mathrm{PD}$ & $0.963(0.602-1.540)$ & \\
\hline & & & Metastatic site & & 0.020 \\
\hline & & & $\mathrm{CR} / \mathrm{PR}$ & 1 & \\
\hline & & & $\mathrm{SD} / \mathrm{PD}$ & $1.850(1.103-3.103)$ & \\
\hline & & & Number of Cycles of Chemotherapy & $0.970(0.930-1.013)$ & 0.167 \\
\hline & & & $\leq 6$ cycles & 1 & 0.746 \\
\hline & & & $>6$ cycles & $0.925(0.578-1.480)$ & \\
\hline Pre-Operation & HR $(95 \% \mathrm{Cl})$ & $p$-value & Surgical Outcomes & $\mathrm{HR}(95 \% \mathrm{Cl})$ & $p$-value \\
\hline BMI & & 0.004 & Peritoneal infiltration & & 0.002 \\
\hline Normal & 1 & & No & 1 & \\
\hline Underweight & $3.538(1.607-7.789)$ & 0.002 & Yes & $2.181(1.343-3.540)$ & \\
\hline Overweight \& obese & $1.073(0.647-1.778)$ & 0.786 & Metastasectomy & & 0.252 \\
\hline Change in CEA level & & 0.009 & No & 1 & \\
\hline Stable & 1 & & Yes & $1.507(0.747-3.039)$ & \\
\hline Improved & $0.410(0.193-0.868)$ & 0.020 & Extent of gastrectomy & & 0.008 \\
\hline Worse & $4.174(1.255-13.881)$ & 0.020 & TG & 1 & \\
\hline NA & $0.856(0.446-1.646)$ & 0.642 & DG & $0.521(0.322-0.842)$ & \\
\hline Change in CA19-9 level & & 0.399 & Extent of LND & & 0.402 \\
\hline Stable & 1 & & $<\mathrm{D} 2$ & 1 & \\
\hline Improved & $1.020(0.437-2.381)$ & 0.963 & $\geq \mathrm{D} 2$ & $0.802(0.480-1.343)$ & \\
\hline Worse & $0.907(0.282-2.911)$ & 0.869 & Complete Macroscopic Resection & & $<0.001$ \\
\hline NA & $0.580(0.309-1.089)$ & 0.090 & Yes & 1 & \\
\hline
\end{tabular}


Table 2 Univariate Cox proportional hazard model of overall survival by each variable (Continued)

\begin{tabular}{|c|c|c|c|c|c|}
\hline Baseline Characteristics & HR $(95 \% \mathrm{Cl})$ & $p$-value & Chemotherapy & HR $(95 \% \mathrm{Cl})$ & $p$-value \\
\hline Pre_op cT stage & & 0.069 & No & $2.348(1.471-3.748)$ & \\
\hline Serosa negative & 1 & & pT stage & & 0.002 \\
\hline Serosa positive & $1.537(0.967-2.444)$ & & Serosa negative (pT1-3) & 1 & \\
\hline Pre_op cN stage & & 0.567 & Serosa positive (pT4a/b) & 2.109 (1.311-3.393) & \\
\hline No/N1 & 1 & & pN stage & & 0.121 \\
\hline N2/N3 & $1.155(0.705-1.894)$ & & $\mathrm{pN} 0 / \mathrm{N} 1$ & 1 & \\
\hline Time interval to surgery & & 0.926 & $\mathrm{pN} 2 / \mathrm{N} 3$ & $1.480(0.901-2.430)$ & \\
\hline$\leq 24$ weeks & 1 & & Lauren classification & & 0.013 \\
\hline \multirow[t]{6}{*}{$>24$ weeks } & $0.926(0.584-1.468)$ & & Intestinal & 1 & \\
\hline & & & Diffuse & $1.960(1.204-3.190)$ & 0.007 \\
\hline & & & Others & $0.867(0.361-2.079)$ & 0.748 \\
\hline & & & Postoperative chemotherapy & & 0.172 \\
\hline & & & No & 1 & \\
\hline & & & Yes & $1.629(0.809-3.281)$ & \\
\hline
\end{tabular}

LN lymph node, NLR neutrophil lymphocyte ratio, SIl systematic immune-inflammation index, $C R$ complete response, $P R$ partial response, $S D$ stable disease, $P D$ progressive disease, BMI body mass index, CEA carcinoembryonic antigen, CA19-9 carbohydrate antigen 19-9, TG total gastrectomy, DG distal gastrectomy, LND lymph node dissection, FU fluoropyrimidine

The bold represents statistical significance

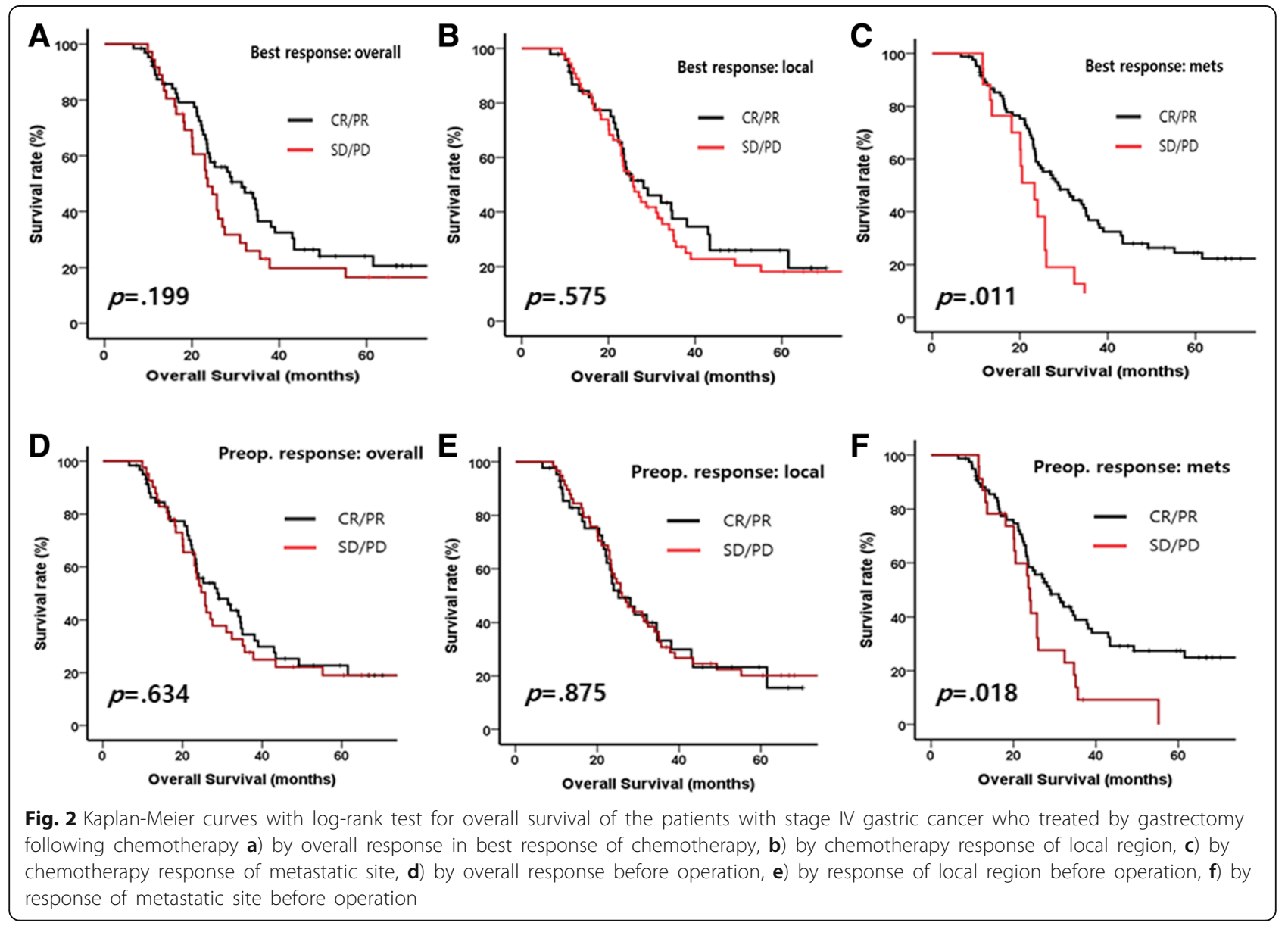



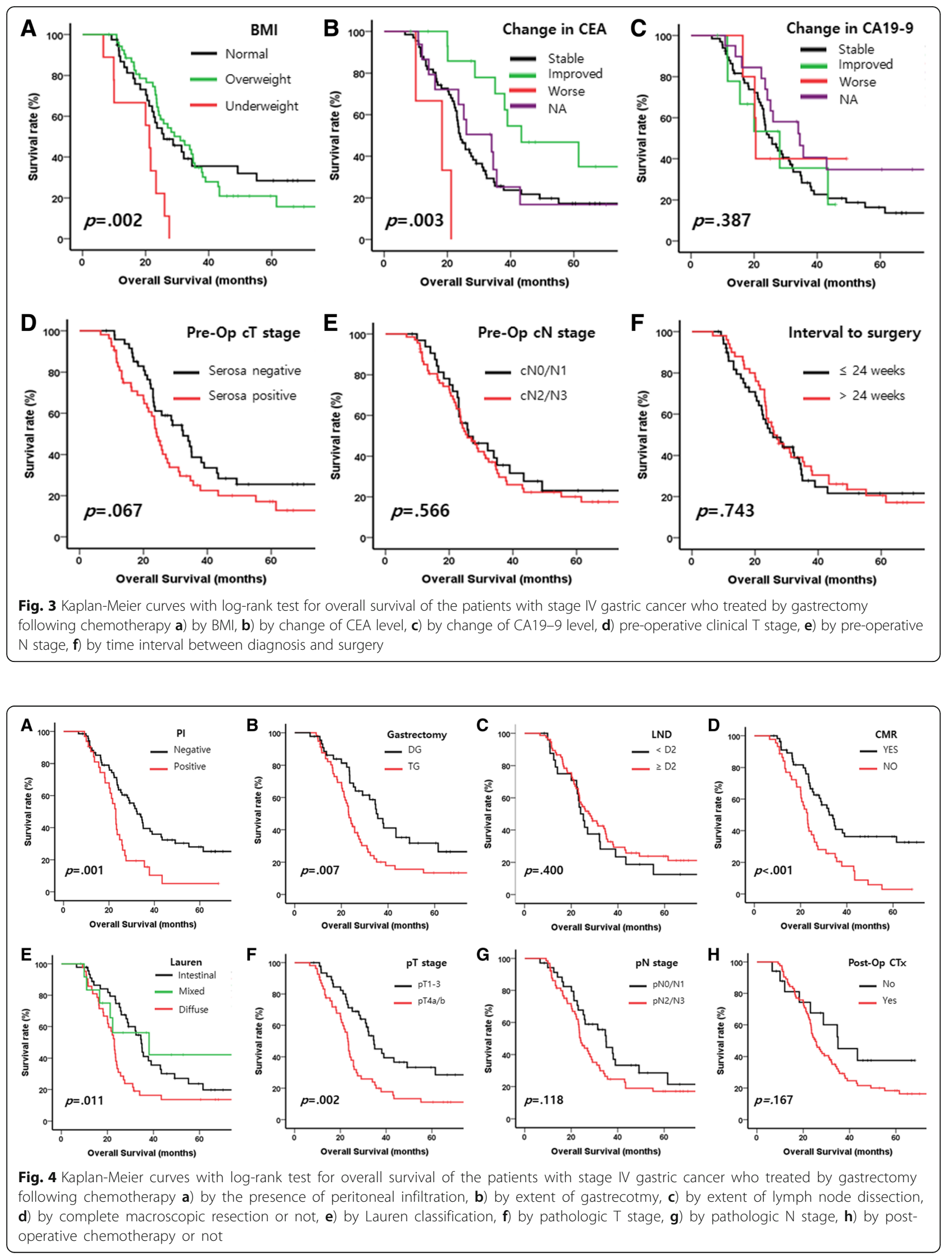
Table 3 Multivariable Cox proportional hazard model of overall survival

\begin{tabular}{llc}
\hline Variables $^{\mathrm{a}}$ & $\mathrm{HR}(95 \% \mathrm{Cl})$ & $p$-value \\
\hline $\begin{array}{l}\text { Best response of metastatic site } \\
\text { CR/PR }\end{array}$ & $\mathbf{0 . 0 5 0}$ \\
$\begin{array}{l}\text { SD/PD } \\
\text { Change of CEA level }\end{array}$ & $1.822(0.999-3.323)$ & \\
$\quad$ Stable & & $\mathbf{0 . 0 2 4}$ \\
Improved & 1 & 0.148 \\
Worse & $0.564(0.259-1.226)$ & $\mathbf{0 . 0 1 0}$ \\
NA & $5.013(1.477-17.017)$ & 0.935 \\
Complete Macroscopic Resection & $0.973(0.504-1.877)$ & $\mathbf{0 . 0 0 5}$ \\
Yes & 1 & \\
No & $1.998(1.233-3.238)$ & \\
\hline
\end{tabular}

$C R$ complete response, $P R$ partial response, $S D$ stable disease, $P D$ progressive disease, CEA carcinoembryonic antigen

${ }^{a}$ the final model was selected by a forward likelihood ratio method from the variables with $p$-value $<0.10$ in a univariate Cox proportional hazard model The bold represents statistical significance

of previous studies of surgical resection after preoperative chemotherapy for initially metastatic gastric cancer are summarized in Table 4 [12-24]. Although the chemotherapy regimens and definitions of gastrectomy varied across the studies, the reported OS ranged 19 to 53 months, which revealed much better outcomes, considering the generally poor prognosis for stage IV gastric cancer. The limitations of the previous studies include small study samples and the use of retrospective methods of analysis. Some of the studies investigated prognostic factors for gastrectomy and presented various factors including R0 resection as significant prognostic factors.

In our study, the median OS of the patients was 26.0 months. Survival outcomes did not differ significantly according to clinical factors at diagnosis including metastatic sites and chemotherapy regimens. In addition to CMR, CEA change as well as the response of metastatic sites to chemotherapy were significant prognostic factors in the multivariable analysis.

Successful curative surgical resection is the most frequently presented prognostic factor of conversion gastrectomy so far. Yabusaki et al. reported that patients obtaining CR/PR to chemotherapy as well as those with R0 resection and D2/D3 LN dissection had longer survival [21]. Fukuchi et al. also demonstrated that $\mathrm{R} 0$ resection as well as one non-curative factor was an independent significant predictor for overall survival in patients who underwent conversion surgery [22]. In general, R0 resection which means that no cancerous cell is seen microscopically in surgical specimen corresponds to resection for cure or complete remission. However, definitive R0 resection is rarely achieved because many cases with stage IV gastric cancer have non-measurable lesions including peritoneal diseases. For example, peritonectomy or pathologic confirmation of residual cancer in surgery for this case is not common surgical procedure in operative field. Our data showed that only $11(10.9 \%)$ of 101 patients underwent metastasectomy with gastrectomy. Thus we defined that curative resection means complete macroscopic resection in abdomen after surgery. Definition of the concept of "conversion therapy" and the patients who are eligible for such a procedure remain to be clarified.

In this study, the response to chemotherapy was important to the prognosis following surgery. Our data showed that the response of the metastatic sites, rather than the overall response, to chemotherapy was a significant prognostic factor. The reason could be related to the original nature of the RECIST evaluation system. We analyzed the chemotherapy response by dividing the response into that of the local region and that of the metastatic sites, adding those responses to the overall tumor response. The local tumor, including the primary stomach cancer and the regional LNs, is mostly evaluated as a non-measurable lesion, and its response is categorized as CR, non-CR/ non-PD, or PD. CR of the primary stomach cancer is seldom observed. For example, although metastatic sites without measurable lesion reveal $C R$, the overall response is not $\mathrm{CR}$ or $\mathrm{PR}$ but is instead non-CR/non-PD in cases in which the local tumor without measurable lesion showed a non-CR/non-PD response. Our results suggest that the chemotherapy response of the metastatic sites is more important than the overall response for the selection of patients who would benefit from conversion gastrectomy.

Our results demonstrate that, in addition to the tumor response assessed grossly, the biochemical tumor response is another significant prognostic factor for OS. Patients with an improved CEA level might obtain a survival benefit from curative surgery subsequent to chemotherapy. In terms of the optimal timing of the surgery, we investigated whether the time interval between chemotherapy and surgery could influence the overall outcome, but the timing was not significant in a univariate analysis.

Recently, the REGATTA trial demonstrated that chemotherapy following palliative surgery for stage IV gastric cancer is not beneficial to survival outcomes based on an interim analysis and the trial was early closed [8]. Surgical resection following chemotherapy has since drawn attention from clinicians who treat patients with gastric cancer to enhance survival. It remains unclear whether conversion gastrectomy improves the prognosis in initially stage IV gastric cancer. The results of our large-scale study combined with those of previous studies demonstrate that conversion surgery after preoperative chemotherapy greatly extended survival for patients with stage IV gastric cancer. Patients who received CMR, showed CR/PR of metastatic sites to chemotherapy, and had an improved CEA level during preoperative treatment could have 
Table 4 Summary the results of gastrectomy following systemic chemotherapy for stage IV gastric cancer

\begin{tabular}{|c|c|c|c|c|c|c|c|c|c|}
\hline \multirow[t]{2}{*}{ Reference } & \multirow[t]{2}{*}{ Author } & \multirow[t]{2}{*}{ Year } & \multirow[t]{2}{*}{ Metastasis } & \multirow[t]{2}{*}{$\begin{array}{l}\text { Regimen of } \\
\text { chemotherapy }\end{array}$} & \multicolumn{2}{|c|}{$\begin{array}{l}\text { Patients who } \\
\text { underwent } \\
\text { gastrectomy }\end{array}$} & \multicolumn{2}{|c|}{$\begin{array}{l}\text { Whole study population } \\
\text { (if it included non-surgery } \\
\text { cases) }\end{array}$} & \multirow[t]{2}{*}{$\begin{array}{l}\text { Prognostic } \\
\text { factors }\end{array}$} \\
\hline & & & & & $\begin{array}{l}\text { Number } \\
\text { of patients }\end{array}$ & $\begin{array}{l}\text { MST } \\
\text { (months) }\end{array}$ & $\begin{array}{l}\text { Number of } \\
\text { patients }\end{array}$ & $\begin{array}{l}\text { MST } \\
\text { (months) }\end{array}$ & \\
\hline 12 & Nakajima et al. & 1997 & M1 & $\begin{array}{l}\text { FLEP (5-Fluorouracil, } \\
\text { Leucovorin, Cisplatin, } \\
\text { Etoposide) }\end{array}$ & 19 & NA & 30 & 6.5 & NA \\
\hline 13 & Yano et al. & 2002 & $\begin{array}{l}\text { unresectable } \\
(\mathrm{M} 0+\mathrm{M} 1)\end{array}$ & $\begin{array}{l}\text { FEMTXP (5-Fluorouracil, } \\
\text { Epirubicin, Methotrexate, } \\
\text { Cisplatin) or THP-FLPM } \\
\text { (Pirarubicin,5-Fluorouracil, } \\
\text { Leucovorin, Cisplatin, } \\
\text { Mitomycin C) }\end{array}$ & 14 & NA & 33 & NA & salvage surgery \\
\hline 14 & Satoh et al. & 2006 & $\mathrm{M0}+\mathrm{M} 1$ & S-1, Cisplatin & 36 & NA & 45 & 21.8 & NA \\
\hline 15 & Ishigami et al. & 2008 & M1 & Paclitaxel, S-1 & 18 & 25.7 & - & - & R0 resection \\
\hline 16 & Okabe et al. & 2009 & $\begin{array}{l}\text { M1 } \\
\text { (peritoneal } \\
\text { metastasis) }\end{array}$ & S-1, Cisplatin & 32 & NA & 41 & 20.4 & NA \\
\hline 17 & Suzuki et al. & 2010 & $\begin{array}{l}\text { unresectable } \\
(\mathrm{M} 0+\mathrm{M} 1)\end{array}$ & Docetaxel, S-1 & 20 & 28.5 & - & - & NA \\
\hline 18 & Kanda et al. & 2012 & M1 & S-1 based chemotherapy & 28 & 29.0 & - & - & $\begin{array}{l}\text { histological } \\
\text { tumor length } \\
(<5 \mathrm{~cm} \text { vs. } \geq \\
5 \mathrm{~cm})\end{array}$ \\
\hline 19 & Satoh et al. & 2012 & M1 & S-1, Cisplatin & 44 & NA & 51 & 19.2 & NA \\
\hline 20 & Han et al. & 2013 & M1 & Various & 34 & $\begin{array}{l}22.9 \text { (R0 } \\
\text { resection) } \\
\text { and } 7.8 \\
\text { (non-R0 } \\
\text { resection) }\end{array}$ & - & - & $\begin{array}{l}\text { ypN stage } \\
\text { (N0-2 vs. N3) }\end{array}$ \\
\hline 21 & Yabusaki et al. & 2013 & M1 & S-1, Cisplatin & 97 & 22.5 & 148 & 16.8 & $\begin{array}{l}\text { surgery, R0 } \\
\text { resection, } \\
\text { D2/D3 lymph } \\
\text { node dissection, } \\
\text { CR/PR response }\end{array}$ \\
\hline 22 & Fukuchi et al. & 2015 & $\begin{array}{l}\text { unresectable } \\
(\mathrm{M} 0+\mathrm{M} 1)\end{array}$ & $\begin{array}{l}\text { S-1, Cisplatin or } \\
\text { S-1, Paclitaxel }\end{array}$ & 40 & 53.0 & 151 & 16.0 & $\begin{array}{l}\text { one non- } \\
\text { curative factor, } \\
\text { RO resection }\end{array}$ \\
\hline 23 & Kinoshita et al. & 2015 & M1 & Docetaxel, Cisplatin, S-1 & 34 & 29.9 & 57 & 20.9 & $\begin{array}{l}\text { potential } \\
\text { resectability }\end{array}$ \\
\hline 24 & Ito et al. & 2015 & M1 & Various & 14 & 24.8 & 70 & 14.1 & NA \\
\hline Present study & & & M1 & Various & 101 & 26.0 & - & - & $\begin{array}{l}\text { curative } \\
\text { resection } \\
\text { (complete } \\
\text { macroscopic } \\
\text { resection), } \\
\text { chemotherapy } \\
\text { response } \\
\text { (CR/PR) of } \\
\text { metastatic site, } \\
\text { change of CEA } \\
\text { level }\end{array}$ \\
\hline
\end{tabular}

considerably better prognosis than those without those factors, suggesting that those factors might be useful selection criteria for conversion surgery. Further investigation is required, however, to determine how to maximize the chemotherapy response.
Our study has some limitations. First, we used a retrospective design to study patients at a single institute. Because of the retrospective design, the preoperative chemotherapy regimen and the timing of the operation varied somewhat. Second, the patients included in our 
study did not represent the whole population of patients with stage IV gastric cancer. Many of the patients who received surgery were likely to have potentially resectable disease at the time of diagnosis, and there might have been a selection bias for patients who respond well to chemotherapy. In addition, only small percent of patients could be received surgery among overall patients with stage IV gastric cancer in that period, therefore, the interpretation of benefit from conversion surgery in the present result should be cautious. Third, there might be a discrepancy between the clinical stage and the true disease dissemination, because metastasis was not pathologically confirmed in most of the patients. Lastly, type II error have to be considered for some subgroup analysis because of small size of cohort in this study.

We evaluated the outcomes of surgery for stage IV gastric cancer in the largest patient group to date and demonstrated that treatment with chemotherapy followed by gastrectomy is feasible and improved long-term survival. Better response (CR/PR) of metastatic sites to chemotherapy, change of CEA level, and CMR were significant prognostic factors.

\section{Conclusion}

In conclusion, although stage IV gastric cancer still has a poor prognosis, our results suggest a practical, multidisciplinary treatment plan for select patients. Large-scale, prospective, multicenter, randomized trials are needed to further determine the best treatment strategy and to elucidate the prognostic role of conversion gastrectomy. Numerous obstacles are yet to be resolved regarding the selection of appropriate patients for conversion gastrectomy, the choice of preoperative/postoperative chemotherapy regimen for obtaining a maximal response, and the optimal timing of conversion surgery.

\section{Additional files}

Additional file 1: Figure S1. Flow chart of patients' recruitment. (TIF $75 \mathrm{~kb}$ ) Additional file 2: Figure S2. Kaplan-Meier curves with log-rank test for overall survival of the patients with peritoneal carcinomatosis by A) by chemotherapy response of metastatic site of, B) change of (EA level, C) complete macroscopic resection or not. (TIF $257 \mathrm{~kb}$ )

Additional file 3: Figure S3. Kaplan-Meier curves with log-rank test for overall survival of the patients with liver metastasis by A) by chemotherapy response of metastatic site, B) change of (EA level, C) complete macroscopic resection or not. (TIF $235 \mathrm{~kb}$ )

Additional file 4: Figure S4. Kaplan-Meier curves with log-rank test for overall survival of the patients with distant lymph node metastasis by A) by chemotherapy response of metastatic, B) change of (EA level, C) complete macroscopic resection or not. (TIF $291 \mathrm{~kb}$ )

Additional file 5: Figure S5. Kaplan-Meier curves with log-rank test for overall survival of the patients with two or more distant metastasis by A) by chemotherapy response of metastatic site, B) change of (EA level, C) complete macroscopic resection or not. (TIF $452 \mathrm{~kb}$ )

\section{Abbreviations}

5-FU: 5-fluorouracil; BMI: Body mass index; CA 19-9: Carbohydrate antigen; CEA: Carcinoembryonic antigen; Cl: Confidence interval; CMR: Complete macroscopic resection; CR: Complete response; HR: Hazard ratio; LN: Lymph node; NLR: Neutrophil lymphocyte ratio; OS: Overall survival; PD: Progressive disease; PR: Partial response; SD: Stable disease; SII: Systemic immuneinflammation index

\section{Acknowledgements}

This research was supported by a faculty research grant from the Yonsei University College of Medicine (6-2007-0095, 6-2008-0193, 6-2016-0115) and the National R\&D program for cancer control, Ministry of Health and Welfare, Republic of Korea (1520190).

\section{Funding}

Not applicable.

\section{Availability of data and materials}

The datasets are available from the corresponding authors on reasonable request.

\section{Authors' contributions}

SHB and YYC collected data, carried out statistical analysis, and drafted the manuscript. SEB, SXL, JSL collected the data and revised the manuscript. TS, HIK, JHC, WJH, SHC, MJ, HSK, HCJ, HCC revised the manuscript and gave the information about surgery and chemotherapy based on their expertise. SYR and SHN participated in the design of the study, analyze the data, and revised the manuscript. All authors read and approved the manuscript.

\section{Ethics approval and consent to participate}

This study was approved by the Institutional Review Board of Severance Hospital, Yonsei University College of Medicine (4-2016-0408). The need for consent to participate has been was waived by the Institutional Review Board because of retrospective design of this study.

\section{Consent for publication}

Not applicable.

\section{Competing interests}

The authors declare that they have no competing interests.

\section{Publisher's Note}

Springer Nature remains neutral with regard to jurisdictional claims in published maps and institutional affiliations.

\section{Author details}

'Department of Internal Medicine, Yonsei Cancer Center, Yonsei University College of Medicine, 50-1 Yonsei-ro, Seodaemun-gu, Seoul 120-752, Republic of Korea. ${ }^{2}$ Department of Surgery, Yonsei Cancer Center, Yonsei University College of Medicine, 50-1 Yonsei-ro, Seodaemun-gu, Seoul 120752 , Republic of Korea. ${ }^{3}$ Department of Radiology, Yonsei University College of Medicine, 50-1 Yonsei-ro, Seodaemun-gu, Seoul 120-752, Republic of Korea. ${ }^{4}$ Key laboratory of Carcinogenesis and Translational Research (Ministry of Education), Department of Gastrointestinal Surgery, Peking University Cancer Hospital \& Institute, Beijing 100142, China.

Received: 17 January 2018 Accepted: 28 October 2018

Published online: 15 November 2018

References

1. Ferro A, Peleteiro B, Malvezzi M, Bosetti C, Bertuccio P, Levi F, Negri E, La Vecchia C, Lunet N. Worldwide trends in gastric cancer mortality (19802011), with predictions to 2015, and incidence by subtype. Eur J Cancer. 2014;50(7):1330-44.

2. Siegel R, Naishadham D, Jemal A. Cancer statistics, 2013. CA Cancer J Clin. 2013;63(1):11-30.

3. Glimelius B, Hoffman K, Haglund U, Nyren O, Sjoden PO. Initial or delayed chemotherapy with best supportive care in advanced gastric cancer. Ann Oncol. 1994;5(2):189-90. 
4. Pyrhonen S, Kuitunen T, Nyandoto P, Kouri M. Randomised comparison of fluorouracil, epidoxorubicin and methotrexate (FEMTX) plus supportive care with supportive care alone in patients with non-resectable gastric cancer. $\mathrm{Br}$ J Cancer. 1995:71(3):587-91.

5. Van Cutsem E, Moiseyenko VM, Tjulandin S, Majlis A, Constenla M, Boni C, Rodrigues A, Fodor M, Chao Y, Voznyi E, et al. Phase III study of docetaxel and cisplatin plus fluorouracil compared with cisplatin and fluorouracil as first-line therapy for advanced gastric cancer: a report of the V325 study group. J Clin Oncol. 2006;24(31):4991-7.

6. Boku N, Yamamoto S, Fukuda H, Shirao K, Doi T, Sawaki A, Koizumi W, Saito $\mathrm{H}$, Yamaguchi K, Takiuchi $\mathrm{H}$, et al. Fluorouracil versus combination of irinotecan plus cisplatin versus S-1 in metastatic gastric cancer: a randomised phase 3 study. Lancet Oncol. 2009;10(11):1063-9.

7. Bang YJ, Van Cutsem E, Feyereislova A, Chung HC, Shen L, Sawaki A, Lordick F, Ohtsu A, Omuro Y, Satoh T, et al. Trastuzumab in combination with chemotherapy versus chemotherapy alone for treatment of HER2-positive advanced gastric or gastro-oesophageal junction cancer (ToGA): a phase 3, open-label, randomised controlled trial. Lancet. 2010;376(9742):687-97.

8. Fujitani K, Yang HK, Mizusawa J, Kim YW, Terashima M, Han SU, Iwasaki Y, Hyung WJ, Takagane A, Park do J, et al. Gastrectomy plus chemotherapy versus chemotherapy alone for advanced gastric cancer with a single noncurable factor (REGATTA): a phase 3, randomised controlled trial. Lancet Oncol. 2016;17(3):309-18.

9. Power DG, Kemeny NE. Chemotherapy for the conversion of unresectable colorectal cancer liver metastases to resection. Crit Rev Oncol Hematol. 2011;79(3):251-64

10. Eisenhauer EA, Therasse P, Bogaerts J, Schwartz LH, Sargent D, Ford R, Dancey J, Arbuck S, Gwyther S, Mooney M, et al. New response evaluation criteria in solid tumours: revised RECIST guideline (version 1.1). Eur J Cancer. 2009;45(2):228-47.

11. Japanese Gastric Cancer A. Japanese gastric cancer treatment guidelines 2010 (ver. 3). Gastric Cancer. 2011;14(2):113-23.

12. Nakajima T, Ota K, Ishihara S, Oyama S, Nishi M, Ohashi Y, Yanagisawa A. Combined intensive chemotherapy and radical surgery for incurable gastric cancer. Ann Surg Oncol. 1997;4(3):203-8.

13. Yano $M$, Shiozaki $H$, Inoue $M$, Tamura $S$, Doki $Y$, Yasuda T, Fujiwara $Y$, Tsujinaka T, Monden M. Neoadjuvant chemotherapy followed by salvage surgery: effect on survival of patients with primary noncurative gastric cancer. World J Surg. 2002;26(9):1155-9.

14. Satoh S, Hasegawa S, Ozaki N, Okabe H, Watanabe G, Nagayama S, Fukushima M, Takabayashi A, Sakai Y. Retrospective analysis of 45 consecutive patients with advanced gastric cancer treated with neoadjuvant chemotherapy using an S-1/CDDP combination. Gastric Cancer. 2006:9(2):129-35.

15. Ishigami S, Natsugoe S, Nakajo A, Matsumoto M, Uenosono Y, Arigami T, Setoyama T, Arima H, Uchikado Y, Kita Y, et al. Salvage gastrectomy following a combination of biweekly paclitaxel and S-1 for stage IV gastric cancer. J Gastrointest Surg. 2008;12(8):1370-5.

16. Okabe H, Ueda S, Obama K, Hosogi H, Sakai Y. Induction chemotherapy with S-1 plus cisplatin followed by surgery for treatment of gastric cancer with peritoneal dissemination. Ann Surg Oncol. 2009;16(12):3227-36.

17. Suzuki T, Tanabe K, Taomoto J, Yamamoto H, Tokumoto N, Yoshida K, Ohdan $\mathrm{H}$. Preliminary trial of adjuvant surgery for advanced gastric cancer. Oncol Lett. 2010;1(4):743-7.

18. Kanda T, Yajima K, Kosugi S, Ishikawa T, Ajioka Y, Hatakeyama K. Gastrectomy as a secondary surgery for stage IV gastric cancer patients who underwent S-1-based chemotherapy: a multi-institute retrospective study. Gastric Cancer. 2012;15(3):235-44.

19. Satoh S, Okabe H, Teramukai S, Hasegawa S, Ozaki N, Ueda S, Tsuji A, Sakabayashi S, Fukushima M, Sakai Y. Phase II trial of combined treatment consisting of preoperative S-1 plus cisplatin followed by gastrectomy and postoperative S-1 for stage IV gastric cancer. Gastric Cancer. 2012;15(1):61-9.

20. Han DS, Suh YS, Kong SH, Lee HJ, Im SA, Bang YJ, Kim WH, Yang HK. Outcomes of surgery aiming at curative resection in good responder to induction chemotherapy for gastric cancer with distant metastases. J Surg Oncol. 2013;107(5):511-6.

21. Yabusaki $H$, Nashimoto A, Matsuki A, Aizawa M. Significance of surgical treatment in multimodal therapy for stage IV highly advanced gastric cancer. Hepatogastroenterology. 2013;60(122):377-81.

22. Fukuchi $M$, Ishiguro $T$, Ogata $K$, Suzuki O, Kumagai $Y$, Ishibashi K, Ishida H, Kuwano H, Mochiki E. Prognostic role of conversion surgery for Unresectable gastric Cancer. Ann Surg Oncol. 2015;22(11):3618-24.
23. Kinoshita J, Fushida S, Tsukada T, Oyama K, Okamoto K, Makino I, Nakamura K, Miyashita T, Tajima H, Takamura H, et al. Efficacy of conversion gastrectomy following docetaxel, cisplatin, and S-1 therapy in potentially resectable stage IV gastric cancer. Eur J Surg Oncol. 2015;41(10):1354-60.

24. Ito S, Oki E, Nakashima Y, Ando K, Hiyoshi Y, Ohgaki K, Saeki H, Morita M, Sakaguchi Y, Maehara Y. Clinical significance of adjuvant surgery following chemotherapy for patients with initially unresectable stage IV gastric cancer. Anticancer Res. 2015;35(1):401-6.
Ready to submit your research? Choose BMC and benefit from:

- fast, convenient online submission

- thorough peer review by experienced researchers in your field

- rapid publication on acceptance

- support for research data, including large and complex data types

- gold Open Access which fosters wider collaboration and increased citations

- maximum visibility for your research: over $100 \mathrm{M}$ website views per year

At BMC, research is always in progress.

Learn more biomedcentral.com/submissions 